\title{
Medio ambiente y salud
}

\author{
TOMÁs Franco*
}

\begin{abstract}
RESUMEN
ABSTRACT

La salud es el resultado de un equilibrio

Health is the result of a dynamic

dinámico entre los organismos y el equilibrium between organisms and the medio del que forma parte. Esta armonía puede romperse de forma natural, pero cada vez es mayor la injerencia humana tanto en el ritmo de los fenómenos (efecto invernadero, capa de ozono o lluvia ácida) como en el reparto de los recursos. El environment of which they are part. This harmony can be broken in a natural way but human interference is growing in the rhythm of phenomena (greenhouse effect, the ozone layer or the acid rain) as well as in the distribution of resources. The desequilibrio económico es la epidemia economic imbalance is the most lethal más letal entre los grupos humanos, cuyo antídoto está sólo en nuestras epidemic among human beings, the antidote of which is only in our hands.

manos.
\end{abstract}

\section{ESTAR Y SENTIRSE BIEN}

La salud es un estado y una sensación positiva del organismo, lo que le permite a éste realizar adecuadamente sus múltiples funciones dentro de un entorno interactivo físico y social. Es un estado en cuanto realidad cambiante que pasa por distintos niveles y es también una sensación positiva, una manera de sentirse bien, la percepción honda y placentera de que el cuerpo y el ánimo llevan idéntico ritmo y que Zubiri denominaba como inteligencia sentiente o sensibilidad inteligente. Todo organismo se realiza actuando sobre un medio, que a su vez lo condiciona o determina, según los casos.

La salud y la enfermedad son experiencias personales únicas e intransferibles, aunque no es menos cierto que ambas transcurren en un

\footnotetext{
* Departamento de Geografía. UNED.
} 
contexto social, en un medio ambiente inevitable, porque tanto éste como la salud son caras de una misma y compleja realidad.

Estar normal es otra manera de disfrutar de una buena salud, pero la normalidad es un concepto dinámico que engloba diversas fluctuaciones, que no por ello se salen de la norma. En el ser humano la temperatura, la presión arterial o la inteligencia varían sensiblemente sin dejar por ello de ser normales. Sólo que tales ondulaciones están siempre contextualizadas en un medio: por ejemplo, quien vive en la costa tiene una cuantía de glóbulos rojos y una presión arterial distintas a las del habitante de la alta sierra.

La salud no es sino un resultado armónico entre el organismo y el medio ambiente. En definitiva, "salud y enfermedad, dos grados extremos en variación biológica, son, pues, la resultante del éxito o del fracaso del organismo para adaptarse física, mental y socialmente a las condiciones de nuestro ambiente total» (San Martín,1979:97).

\section{LA SALUD COMO UN RESULTADO DEL EQUILIBRIO CON EL MEDIO AMBIENTE}

Si la salud es una realidad dinámica que transcurre por diversas etapas o niveles, parece evidente que poseerla es hallarse en equilibrio consigo mismo y con el entorno. Así lo demuestra un estudio canadiense, confirmado luego en otros países. En dicho trabajo la salud aparece vinculada al medio ambiente (33\%), al estilo de vida (33\%), al sistema de asistencia sanitaria $(20 \%)$ y a la biología humana $(14 \%)$. Veamos con cierto detalle cada uno de estos cuatro factores.

a) El medio ambiente, que luego se analizará con mayor extensión, tiene un tercio de incidencia sobre la salud, aumentando o disminuyendo su repercusión según sea el estilo de vida del organismo, que eso es lo que significan los trazos intermitentes entre ambos (Fig. 1). La contaminación del medio incide sobre las aguas, el aire, el suelo o las relaciones psicosociales a través de la biologia (polen, bacterias, hongos y virus); de la física (polvo, ruido, humos y desechos); de la química (azufre, hidrocarburos y mercurio) y del ambiente social (violencia, promiscuidad sexual, prisas, competitividad, estrés, etc). (Piédrola y otros, 1991).

b) El estilo de vida tiene sobre la salud una repercusión similar a la del medio ambiente y aspectos destacables de aquél son los hábitos alimenticios (abuso de grasas e hidratos de carbono), la falta de ejercicio fí- 


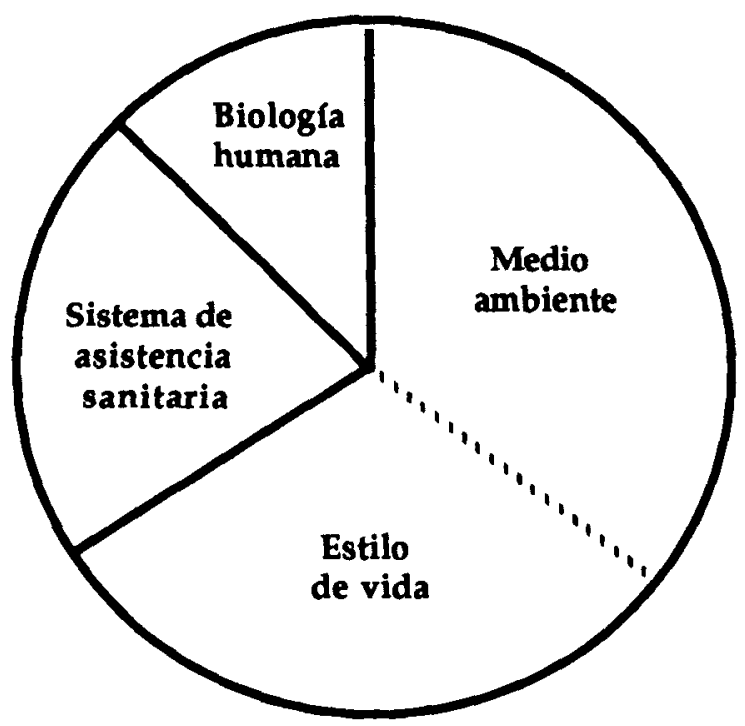

Figura 1. Efecto relativo de cada una de las variables sobre la salud (Piédrola y otros 1991:7).

sico, el consumo de drogas permitidas (tabaco y alcohol) o no (cocaína y heroina) y la conducción peligrosa, entre otros.

c) El sistema sanitario posee una menor incidencia general, aunque en algunos colectivos y en determinadas circunstancias resulte decisivo según sea su nivel de calidad, cobertura, gratuidad o rapidez en sus prestaciones (Salleras, 1989).

d) La biologia humana es el factor menos decisivo para la salud, sin embargo tiene el comportamiento más rígido del grupo, pues sus pautas, marcadas por la herencia, son apenas modificables posteriormente.

\section{INVERSIÓN PÚBLICA EN LA SALUD}

Si interesante es la figura 1, no lo es menos la 2 donde aparece la importancia relativa de la inversión pública en cada uno de los distintos factores que enmarcan la salud. La asistencia sanitaria, que sólo repercute en un $14 \%$ sobre ésta, acapara el $85 \%$ de los recursos totales. El estilo de vida y el medio ambiente, con dos tercios de la responsabilidad, han de conformarse con el $3,5 \%$ para cada uno. El resto $(8 \%)$ queda para la biologia. 


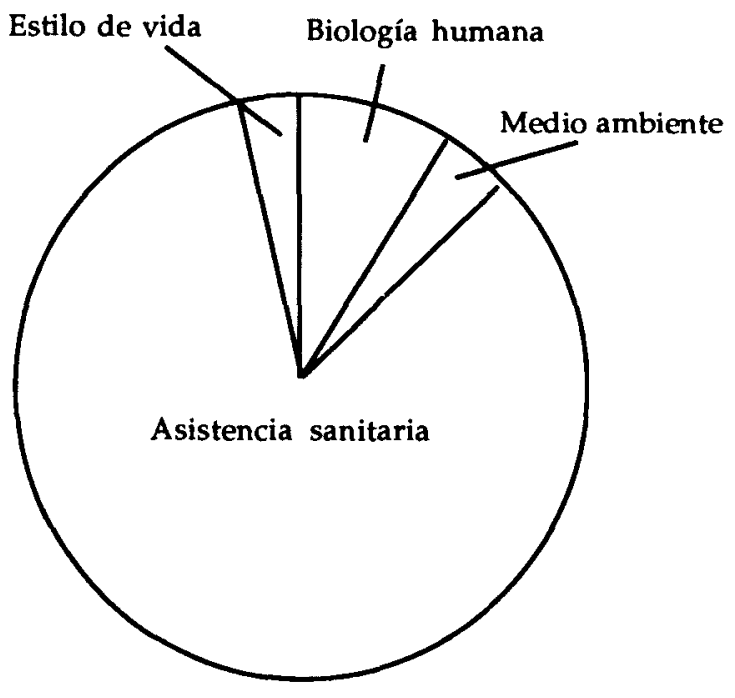

Figura 2. Proporción relativa de dinero público gastado en las diversas actividades (Piédrola y otros, 1991:8).

Este sencillo gráfico permite numerosas reflexiones sobre la política sanitaria, asignación y rentabilidad de los recursos, prioridades en la atención al medio ambiente, etc.

Durante siglos los avances generales en el tema de la salud fueron muy lentos. A partir del siglo xIX se fueron consiguiendo importantes logros con el descubrimiento de vacunas, la erradicación del hambre de entre la mayoría de la población así como por la práctica generalizada de usos higiénicos hoy elementales. El paso de una baja sanidad de carácter tradicional a otra más avanzada de corte moderno pasa por tres estadios: en el primero, que corresponde a los inicios del desarrollo industrial, predominan las enfermedades infecciosas endémicas como la gastroenteritis, malnutrición y parasitosis.

En el segundo, y una vez alcanzado un desarrollo medio, abundan la tosferina, el sarampión, la poliomielitis y otras enfermedades bacterianas y víricas. Finalmente, en el más alto nivel, la mortalidad infantil deja paso a la de ancianos debido a "las enfermedades degenerativas de la naturaleza cerebroesclerótica, tales como la hipertensión, los fallos del corazón, la diabetes, las enfermedades psicosomáticas y el cáncer» (Barney, 1982:384). En este último estadio la población ha pasado de tener hambre a comer en exceso. 


\section{CONTAMINACIÓN NATURAL Y ANTRÓPICA}

Para muchos el medio ambiente es sinónimo de naturaleza inagotable, cuyos infinitos recursos podemos gastar sin tiento. Desde su sensibilidad lo perciben, incluso, como algo ajeno y extraño, cuando no hostil a sus exigencias más inmediatas y primarias. Pensemos, a modo de ejemplo, en la opinión generalizada sobre el buen o mal tiempo asociados, respectivamente, a la ausencia o presencia de lluvias. Sin embargo el medio ambiente es una realidad compleja y entrañable, porque el aire que respiramos pasa a formar parte de nosotros mismos e igual ocurre con el agua y con otros elementos del entorno.

Más que estar en un medio habría que hablar de ser parte del mismo. Recordemos las reflexiones del emperador Adriano en sus Memorias, cargadas de sensibilidad y de sorpresa ante la interacción entre el mundo animado e inanimado, entre la materia y el espíritu:

\footnotetext{
"Comer un fruto significa hacer entrar en nuestro Ser un hermoso objeto viviente, extraño, nutrido y favorecido como nosotros por la tierra; significa consumar un sacrificio en el cual optamos por nosotros frente a las cosas. Jamás mordí la miga de pan de los cuarteles sin maravillarme de que ese amasijo pesado y grosero pudiera transformarse en sangre, en calor, acaso en valentía" (Yourcenar, 1983:13).
}

Estamos acostumbrados a que la naturaleza nos proporcione gratuitamente numerosos bienes (alimentos, minerales u oxígeno) y servicios (acción depuradora del viento o del bosque), pero los cambios habidos en ella durante las últimas décadas parecen confabularse contra nuestra salud. El medio ambiente ha dejado de ser un regazo maternal y vivificante para tornarse en hostil y aun peligroso.

El $95 \%$ de la materia viviente está integrado por seis elementos: azufre, carbono, fósforo, hidrógeno, nitrógeno y oxígeno. De ellos los dos primeros y el penúltimo han sufrido desequilibrios importantes. El medio ambiente mundial ha entrado en una fase inquietante para la salud humana y para el resto de los organismos vivientes. Una buena prueba de ello son: el crecimiento del agujero de ozono, las lluvias ácidas, el accidente nuclear de Chernobil o la muerte de miles de lagos en Canadá y Suecia.

Es cierto que la Naturaleza es un inmenso y permanente foco de contaminación como puede comprobarse en las erupciones volcánicas o en la expulsión a la atmósfera de miles de toneladas de partículas de sal por los océanos, pero no lo es menos que ella misma cuenta con instrumentos para encauzarla restaurando el equilibrio. Por otro lado, la suya es una 
contaminación diluida a escala planetaria. El hecho es que durante miles de millones de años ha conseguido crear unas formas de vida perfectamente adaptadas al medio prescindiendo de numerosos compuestos orgánicos (los clorados) o protegiendo las células vivas de metales tan mortíferos como el mercurio.

Pero el hombre, cuya atracción hacia lo prohibido y peligroso forma parte de su esencia, ha fabricado cientos de miles de productos químicos sobre los que mantiene un escaso control. Actualmente manipula unos 40.000 y si tuviera que hacerse un estudio sobre la incidencia de los mismos en el medio ambiente, como por otro lado parece lógico, todos los laboratorios actuales tendrían que estar trabajando en ello durante casi un siglo, según la OIT. Por ejemplo, conocer el grado de toxicidad de cualquiera de estos productos le supone a un laboratorio norteamericano cinco años de experimentos con animales y una inversión de medio millón de dólares (Bermejo, 1994).

La contaminación que origina el hombre tiene además otro inconveniente añadido y es su concentración en áreas muy reducidas $y$, por lo general, las más densamente pobladas. El deterioro a que se ha visto sometida la Naturaleza en estos dos últimos siglos no sólo es importante por su volumen y diversidad sino también porque tiene, además del tecnológico, un marcado carácter socioeconómico. Si los aerosoles, humos, partículas sólidas, vertidos contaminantes o desechos de todo tipo supo nen una agresión reiterada al medio ambiente, no lo es menos el clima socioeconómico que la alimenta. Estamos inmersos en un sistema, el capitalista, cimentado en el beneficio y el consumo y que, escudándose tras la libertad de mercado, ha dividido la economia mundial en dos grandes bloques: el Centro, integrado por los países que controlan la tecnología punta, el capital y las armas disuasorias y la Periferia, donde se alinean todos los demás, cuya función consiste en proporcionar a los primeros materias primas y mano de obra baratas a la vez que compra a un alto precio los productos manufacturados que precisa.

\section{EL ECOSISTEMA HUMANO}

A finales del siglo xix Haeckel definió la ecología como la ciencia que estudia las relaciones de los seres vivos entre sí y de éstos con el medio que los rodea. El resultado son los ecosistemas naturales entre los que está el humano, sin duda el más complejo por su diversidad y alcance, pues se extiende por toda la tierra. Todos ellos quedan circunscritos al ámbito de la Biología, pero el ecosistema humano trasciende los aspectos 
biológicos e invade los psicosociales y los socioeconómicos. Las costumbres y los modos de vida pueden llegar a ser más decisivos para la salud humana que los factores ambientales físicos o biológicos.

De lo anterior deducimos que el ecosistema es una organización dinámica de las formas de vida (bioma) en un territorio reducido que posee un clima homogéneo. Cualquier organismo, excepto el hombre, tan sólo cuenta con su capacidad de adaptación inmediata (mecanismos reflejos) 0 mediata (modificaciones genéticas) para mantenerse en equilibrio con el medio ambiente. El hombre es un caso aparte porque, en sus relaciones con aquél, interpone la inteligencia con la que lo modifica para su beneficio inmediato. El problema, según veremos, está en si también le beneficiará en el futuro.

Entre los animales, los más débiles mueren enseguida o se les expulsa de la cadena reproductora. En el hombre el esquema no es tan rígido porque entran en juego otros valores de comportamiento ético, aunque también éstos se mantienen en un equilibrio precario del que son reflejo las explosiones de racismo, la xenofobia, el abandono de los ancianos o la insolidaridad con los parados.

Todos los organismos que integran un ecosistema forman lo que denominamos cadena trófica, desde los factores abióticos (suelo, atmósfera o minerales) hasta los carnivoros, pasando por el edafón (flora, fauna y microorganismos) y los herbivoros. Existe una profunda analogía entre ecosistema y organismo, ya que ambos precisan de diversos grados de organización interdependientes. También les es común un mismo proceso evolutivo y degenerativo.

El hombre es una parte decisiva en la permanencia y modificación de numerosos ecosistemas. Hasta fechas recientes su capacidad de influencia, más bien escasa, ha ido pareja con el nivel de desarrollo conseguido. Su primer impacto llegó con la agricultura al destruir amplios ecosistemas sobre cuyo territorio implantar otros nuevos de carácter artificial. Pero es con la urbanización generalizada y la industrialización en masa cuando empieza a cambiar el equilibrio natural de manera contundente.

Numerosos ecosistemas desaparecen y surgen otros nuevos vinculados con las grandes presas, los fertilizantes, los pesticidas, los complejos industriales o los desechos urbanos. Es preciso un conocimiento muy profundo sobre los diversos aspectos de los ecosistemas para poder prever resultados, conseguir rendimientos o evitar catástrofes. En esa línea sería muy interesante investigar sobre el balance energético, las cadenas alimentarias y la incidencia de determinados procesos en la evolución de los ecosistemas. 
En cada ecosistema los factores ambientales de mayor influencia son "la intensidad y duración de la luz, composición espectral de la luz incidente y de la filtrada a través de las hojas, temperatura, velocidad del viento, lluvia, rocío, contenido en dióxido de carbono del aire y del suelo, composición química, estructura física y contenido en oxígeno de los suelos" (Evenari, 1973:143). Puesto que los españoles vivimos en un medio árido, sería de gran interés para nosotros conocer, sobre todo, el uso que hacen del agua algunos ecosistemas perfectamente adaptados a la sequía porque estamos condenados, cada vez más, a vivir en ámbitos artificiales.

La agricultura, por ejemplo, es el resultado de la creación de numerosos ecosistemas artificiales, subordinados exclusivamente a la rentabilidad. Convendría, sin embargo, llegar a la convicción de que en muchas ocasiones la agricultura está reñida con la pervivencia del propio ecosistema y del medio ambiente. Más aún, hay que dejar constancia de que una rentabilidad óptima no tiene por qué ser la que genere los mayores beneficios momentáneos sino la que consiga mantener el equilibrio medioambiental. Del millón de especies vegetales existentes, sólo utilizamos una mínima parte en la agricultura. Nos queda pues un inmenso futuro por delante para hallar nuevas posibilidades insospechadas.

\section{EL MEDIO AMBIENTE Y SU INCIDENCIA EN LA SALUD}

Los aspectos sobre el medio ambiente que inciden en la salud humana son múltiples. Veamos los más importantes desde el punto de vista físico (biosfera) y socioeconómico (sistema capitalista).

\subsection{La incidencia del clima}

El clima se define como el estado medio de la atmósfera analizado durante un largo periodo de tiempo, no inferior a 30 años, y referido a una superficie o zona determinada. Desde el punto de vista de la salud, en él se da una serie de circunstancias ambientales que posibilitan la vida humana. Algunas de estas circunstancias son inalterables, como el relieve, la composición del suelo, los cursos de agua o la localización geográfica, pero otras varían dentro de la uniformidad que traza el clima: son las lluvias, los vientos, la nubosidad, la insolación o las cosechas.

Las condiciones climáticas benignas y la fertilidad del medio han permitido el desarrollo de los grupos humanos en sus tres actividades primi- 
genias: la recolección, caza y pesca, la agricultura y la ganadería. El crecimiento poblacional en sus inicios estaba regulado con cierta tiranía por las fuerzas de la naturaleza. Sólo la técnica, a partir de la Revolución Industrial, ha roto este equilibrio milenario. Pero dejando a un lado, de momento, los aspectos económicos, el clima sigue teniendo una importancia destacable en la salud.

Analicemos, con unas gruesas pinceladas, las peculiaridades más notorias del clima peninsular y sus posibles repercusiones en la salud. Existen tres grandes ámbitos climatológicos: el oceánico, el mediterráneo $y$ el interior continental.

a) El clima oceánico festonea la costa cantábrica y atlántica desde el País Vasco hasta el suroeste gallego, sin penetrar apenas en el interior, pues se interponen la Cordillera Cantábrica y los Montes Leoneses. Las temperaturas son suaves durante todo el año, sin que ningún mes aproxime sus medias a los $0{ }^{\circ} \mathrm{C}$ en invierno ni sobrepase los $20^{\circ} \mathrm{C}$ en verano. Las lluvias superan los 1.000 litros por $\mathrm{m}^{2}$ al año y ningún mes sufre una verdadera sequía como ocurre en el resto del país (Franco, 1996). Consecuentemente, todo el territorio que disfruta de este clima oceánico aparece verde, tiene un claro superávit de lluvias y está masivamente cubierto por masas boscosas de hayas, castaños, robles, pinos y eucaliptos, estos últimos en Galicia. La humedad ambiental es grande y persistente, lo que favorece el reúma y la tuberculosis, hoy de escasa incidencia.

b) El clima mediterráneo se extiende desde la costa gerundense hasta Huelva sin adentrarse profundamente hacia el interior, salvo en Andalucía. Se caracteriza por disfrutar de unas temperaturas suaves en invierno y cálidas en verano, que pueden llegar a calurosas en el sur y sureste. Las lluvias, siempre escasas, se concentran en los equinoccios de otoño y primavera. En invierno llueve poco por estar la zona bajo la influencia del anticiclón frío continental y en verano menos aún al transcurrir hasta cuatro meses en absoluta sequía. Las precipitaciones son de gran intensidad horaria, es decir, caen torrencialmente en un corto espacio de tiempo, originando siempre alguna catástrofe sobre las tierras sedientas y desprotegidas de vegetación después de un largo y tórrido estío.

Es una zona que posee un especial atractivo para el descanso y el ocio durante todo el año. De hecho se ha convertido en el punto de encuentro vacacional para decenas de millones de europeos y en el puerto donde desembarcan muchos de los jubilados ingleses, alemanes y nórdicos para vivir los últimos días hasta su postrera travesía en la barca de Caronte. Sin embargo, la zona ha sido considerada durante siglos como de alto riesgo debido a las numerosas epidemias que producían las aguas 
encharcadas, auténticos pudrideros durante el seco y caluroso verano. Hoy es todo el Mediterráneo el que parece condenado a convertirse en un mar muerto por los vertidos industriales y urbanos de todos los paises ribereños.

Cada año recibe cerca de 700.000 toneladas de petróleo, de las que un $70 \%$ son derrames deliberados de operaciones rutinarias llevadas a cabo por petroleros y refinerías. Pero ésta es sólo una pequeña parte de los volúmenes de contaminación que sufre, pues los análisis realizados sobre delfines muertos en las playas españolas mostraban niveles altísimos de compuestos tóxicos como los PCBs, el cloro y los derivados de la celulosa (López de Uralde, 1992).

c) El clima continental abarca las dos mesetas y el Valle del Ebro, es decir, las Comunidades de Castilla-León, Castilla-La Mancha, Madrid y Aragón, tierras del interior peninsular rodeadas por montañas que dificultan la influencia agradable y moderadora tanto del Atlántico como del Mediterráneo. Las temperaturas son frías en invierno y calurosas en verano, especialmente en la Meseta Sur y Valle del Ebro. La primavera es corta y desapacible y el otoño prolonga y suaviza los calores veraniegos hasta bien entrado noviembre. Las lluvias otoño-invernales se alargan durante la primavera y la habitual sequía veraniega, debida al anticiclón de las Azores, es interrumpida por alguna tormenta de carácter convectivo que, con harta frecuencia, deja las cosechas destrozadas a su paso. "En esta zona, en invierno, las enfermedades del aparato respiratorio y las secuelas respiratorias son frecuentes y graves, así como los accidentes cardiovasculares y cardíacos» (Piédrola y otros, 1991:176).

\subsection{La contaminación atmosférica}

Entendemos por tal el efecto negativo que ejerce el hombre sobre el aire, un elemento indispensable para la vida sobre la tierra. Es la presencia en la atmósfera de materias o formas de energía que impliquen riesgo, daño o molestia grave para las personas y bienes de cualquier naturaleza, según la literatura oficial.

El aire se compone de diversos elementos, entre los que la presencia de nitrógeno $(78 \%)$ es determinante. Le siguen a gran distancia el oxígeno $(20,9 \%)$ y después otros muchos, como el argón, neón, helio, metano, etc., en cantidades tan escasas como imprescindibles. En la contaminación atmosférica hay que tener en cuenta tres aspectos: qué clase y cuantía de contaminantes se envían a la atmósfera, cuáles son las condiciones 
ambientales al recibir dichos contaminantes y, en tercer lugar, cómo inciden sobre la salud humana y sobre el resto de la vida vegetal y animal.

La contaminación atmosférica ha acompañado al hombre desde que éste se concentró en núcleos de cierta importancia a partir de la primera revolución agrícola en el neolítico. La falta de higiene personal, los detritus y basuras por las calles y la mezcla de viviendas y establos bajo un mismo techo son algunos fenómenos inseparables de nuestra historia. Recordemos las ciudades medievales apiñadas tras sus murallas con caIlejuelas estrechas y malolientes. En ellas eran tan frecuentes como letales las explosiones del cólera y de otras enfermedades contagiosas.

Pero sin retrotraer la memoria tantos siglos, sirva de ejemplo la aldea de nuestra infancia o algunos pueblos actuales en la serranía abulense, de los Ancares o de Sierra Morena. La contaminación de forma masiva hay que asociarla con la revolución industrial de finales del siglo XVIII, aunque es a partir de la segunda guerra mundial cuando se toma verdadera conciencia sobre la misma.

a) Tipos de contaminantes. En la atmósfera existe un volumen de contaminación de origen natural muy superior a la producida por el hombre, pero tiene sus propios sistemas de desactivación, como hemos dicho con anterioridad. No ocurre lo mismo con la de origen humano por su carácter artificial y porque se acumula en una superficie reducida sobre las ciudades. Los principales focos de contaminación son el transporte privado y público y las actividades industriales, agrarias y urbanas.

- El monóxido de carbono (CO) es el más abundante en la atmósfera y procede tanto de los aportes naturales (66\%) como de los humanos $(34 \%)$. Éstos tienen su origen en la combustión incompleta de materiales ricos en carbono, en los vertederos de basura o en la ganadería, y los naturales, en la oxidación del metano al descomponerse anaeróbicamente la biomasa vegetal y animal, entre otras fuentes naturales del citado gas.

- El dióxido de azufre $\left(\mathrm{SO}_{2}\right)$ procede casi en un $50 \%$ de la actividad humana por la combustión del fuel-oil y del carbón, fundición de minerales, etc.

- Los óxidos de nitrógeno son el óxido nitroso $\left(\mathrm{N}_{2} \mathrm{O}\right)$, el óxido nítrico (NO) y el óxido de nitrógeno $\left(\mathrm{NO}_{2}\right)$. Los dos primeros tienen su origen en la propia naturaleza y su importancia estriba en la colaboración que prestan para la formación del óxido de nitrógeno, de procedencia netamente humana (combustiones) y de efectos nocivos.

- Finalmente están las partículas (entre $0,1 \mu \mathrm{m}$ y $10 \mu \mathrm{m}$ de diámetro) en suspensión que provienen de las erupciones volcánicas, incendios, 
sales marinas o humos industriales y que pueden tener una gran repercusión sobre la salud humana al penetrar en los pulmones.

b) Las condiciones atmosféricas son el segundo aspecto a tener en cuenta al analizar la contaminación. La atmósfera, y más concretamente la troposfera o capa inferior de aquélla, es una zona muy compleja donde sucede la mayor parte de los fenómenos que afectan a la vida sobre la tierra, tales como la humedad, temperatura, vientos, presión, precipitaciones o nubosidad.

El volumen de las precipitaciones y su intensidad, las horas de insolación anual o las de ciclo cubierto, la presión atmosférica, la frecuencia o no de inversiones térmicas, etc. son otros tantos fenómenos que nos indican la importancia de la climatología en todo cuanto hace referencia a la contaminación atmosférica.

c) La capa de ozono. El ozono $\left(\mathrm{O}_{3}\right)$ es una forma de oxígeno que se encuentra en la atmósfera en una pequeñísima proporción, pero cuya incidencia sobre la salud es definitiva. Se produce en la estratosfera debido a la intensa actividad fotoquímica allí existente. Su función consiste en hacer de filtro natural frente a los rayos ultravioleta solares porque si éstos llegasen tal y como los irradia el sol destruirían la mayor parte de la vida terrestre. EI agujero registrado en la última década sobre la Antártida y en otras zonas del planeta ha permitido a los investigadores calcular sus efectos: unos 700.000 cánceres de piel y 1,6 millones de cataratas (El País, 5/3/1992).

Las causas de su desaparición parecen deberse a fluctuaciones atmosféricas, pero sobre todo $-y$ esto último está perfectamente demostrado- a la acción de los clorofluorocarbonos (CFC) que se utilizan en los esprais de aerosoles, gas de las neveras o espumas que arrojan los bomberos para apagar los incendios. La comunidad internacional está muy sensibilizada contra estos productos y ha pedido su eliminación para el año 2000, pero los paises menos desarrollados han solicitado que los avanzados les proporcionen alternativas técnicas ya que son éstos los verdaderos responsables de la situación actual. Acabamos de ver en Kioto que el problema es irresoluble desde planteamientos estrictamente económicos. Como tantas veces en la historia de la humanidad, y en la propia, sólo aprendemos desde la tragedia y el sufrimiento.

\subsection{La incidencia sanitaria de otros fenómenos medioambientales}

Entre los diversos fenómenos destacamos el efecto invernadero, el monóxido de carbono, algunos óxidos y la lluvia ácida. 
- El efecto invernadero es otro de los graves problemas atmosféricos que se están planteando sobre la vida de la tierra: durante el día las tierras y los mares reciben del sol un determinado volumen de calor que durante la noche irradian al espacio - no en su totalidad- en forma de rayos infrarrojos de onda larga. Si la capa atmosférica se vuelve excesivamente compacta por las partículas de dióxido de carbono $\left(\mathrm{CO}_{2}\right)$, óxido nitroso $\left(\mathrm{N}_{2} \mathrm{O}\right)$, metano $\left(\mathrm{CH}_{4}\right)$ y otros contaminantes, no es posible o se hace muy difícil la refrigeración adecuada de la tierra, que poco a poco se va calentando. Se calcula que en los últimos 30 años la temperatura ha ascendido $0,7^{\circ} \mathrm{C}$. A este ritmo, hacia el año 2050 la tierra tendrá entre 2 y $5^{\circ} \mathrm{C}$ más de media. Las consecuencias pueden ser catastróficas, pues al licuarse parte de los hielos se elevará un metro el nivel de las aguas oceánicas cubriendo amplias zonas costeras, desaparecerá gran parte de los bosques templados sin tiempo para aclimatarse a las nuevas condiciones térmicas y lo mismo ocurrirá con numerosas especies ante cambios tan bruscos.

- Monóxido de carbono. Por todos es conocida su toxicidad puntual si se inhala directamente, pero para nuestro análisis este aspecto carece de interés por su mínima frecuencia. Importa más conocer sus efectos a medio y largo plazo en lugares donde la concentración es baja pero continuada, como en las ciudades. Los resultados no son aún concluyentes, pero las investigaciones realizadas señalan que los rendimientos laborales son más bajos, las cefaleas entre sujetos sanos, más frecuentes y las dolencias cardiovasculares se agudizan entre quienes presentan algunos síntomas previos.

- Óxidos de nitrógeno, hidrocarburos y óxidos de azufre. Los estudios realizados acerca de la incidencia de los óxidos sobre las plantas, animales y hombres no son todavía muy precisos porque exigen un periodo largo de exposición a los mismos y no es fácil separar unas influencias de otras. Sólo en casos muy puntuales y de signo catastrófico se han encontrado pruebas fehacientes de su peligrosidad. Tal fue el caso de Londres en el año 1952 o el del Valle del Mosa en 1930. En ambas situaciones de fuerte contaminación atmosférica se dispararon las defunciones entre ancianos y niños por bronquitis y afecciones pulmonares. La relación entre el cáncer pulmonar y la contaminación atmosférica tampoco parece concluyente. Sin embargo, los efectos nocivos del tabaco no ofrecen ya la menor duda científica.

- La lluvia ácida es el fenómeno más conocido de la contaminación atmosférica por las graves consecuencias que está ocasionando en los países desarrollados de Europa y América del Norte. Entre sus efectos 
están la acidificación de las aguas superficiales, la desaparición de grandes superficies boscosas (entre un 15 y un $30 \%$ de los bosques europeos están muertos o profundamente dañados) y la degradación del suelo, que para recuperarse necesita cientos de años en óptimas condiciones.

\section{EL FRACASO MEDIOAMBIENTAL DEL SISTEMA ECONÓMICO}

El hundimiento de la economía planificada, o socialismo del Este, es un hecho no asimilado todavía sociológicamente por haber sido durante décadas como un muro de referencia obsesiva y contrapunto ideológico y económico. Pero tal incertidumbre carecería de importancia si detrás de ella no existiese el hecho más que probable de que el equilibrio global se ha vuelto algo más precario.

El triunfo del capitalismo, como suele ocurrir a menudo en el ámbito más reducido de la política de un país, no se debe tanto a la suma de aciertos propios como a la multiplicación de los errores ajenos. Detrás de una ideología, basada en la justicia social, la solidaridad y la igualdad, se ocultaba un voraz capitalismo de Estado. El edificio socialista se ha hundido por aluminosis interna más que por la convicción generalizada de las bondades del sistema capitalista. Pero si éste quiere ser consecuente con sus propios planteamientos de antimonopolio y competitividad, debería ayudarlo a levantarse, aunque con unas estructuras más genuinas, y utilizarlo como liebre para estimularse en la carrera por el logro de sus fines últimos. Sin duda es ésta una reflexión utópica. Con toda seguridad, mal futuro les aguarda a los más débiles bajo el monopolio de nuestro mundo capitalista teniendo en cuenta los últimos datos sobre la evolución de la economía mundial.

A finales de la década de los 80 , el PIB por habitante de los diez países más pobres era cien veces inferior al de los más ricos. En esta misma década, las diez naciones más ricas concentraban el $83 \%$ de la producción mundial y tres de ellas (EE.UU., Japón y la antigua República Federal de Alemania), el $50 \%$. Si en 1965 la renta de los paises más desarrollados era 15 veces superior a la de los más pobres, en 1990 la distancia se habia elevado a 33, o dicho de forma más sencilla: en la primera fecha los países pobres disponían de 6,6 dólares por cada 100 en manos de los más ricos. Veinticinco años después, aquéllos seguían con sus escasos 7 dólares mientras éstos los habían aumentado a 220.

Pero no se acaban aquí las diferencias sino que se agudizan si tenemos en cuenta que en 1991 la deuda de los países pobres con los ricos 
ascendía a 1,3 billones de dólares, lo que suponía el $21 \%$ de los ingresos totales del África subsahariana y el $40 \%$ de Latinoamérica. Todo esto ha desembocado en que unos 3.000 millones de personas estén mal alimentadas o pasen hambre porque la producción mundial de alimentos crece anualmente un $1 \%$ mientras la población lo hace un $3 \%$.

Estos son algunos de los datos que jalonan el camino de nuestro sistema económico, en modo alguno discordantes con sus planteamientos básicos: un Centro articulado, autónomo y sin graves tensiones y una Periferia cuyo desarrollo es nodular, desarticulado y dirigido hacia la exportación de materias primas, como se comentó anteriormente. Las perspectivas, sin embargo, no se presentan muy halagüeñas porque las tensiones son múltiples, si bien es cierto que se van resolviendo a través de conflictos tan violentos como controlados, de momento. Es inevitable que la situación mundial sea estructuralmente explosiva porque si el $80 \%$ de los miembros de nuestra especie son pobres y pasan hambre, no podemos tener la esperanza de vivir en un mundo de paz.

Que en la Periferia haya estos continuos estallidos, nos hemos acostumbrado a verlo como algo lógico. No lo parece tanto la existencia de 20 millones de pobres en los EEUU o de 52 millones en la UE, considerados como tales aquellos que obtienen una renta por debajo de la mitad de la media dentro de su propio país. Pero no existe tal contradicción si recordamos que la búsqueda permanente del máximo beneficio, y no la solidaridad o el ecodesarrollo, es el motor que impulsa nuestro sistema económico.

Estudios recientes dan para nuestro país una cifra de pobres en torno a los 8.000 .000 de personas. No sólo avanza la pobreza entre las capas más bajas de la sociedad, sino que también se acrecienta el número de menesterosos o de personas que viven en la miseria. Para establecer las diferencias que hay entre ambas categorías, llamamos pobres a quienes tienen unos ingresos en torno al $50 \%$ de la media por persona y menesterosos cuando su renta queda por debajo del $25 \%$ de los ingresos medios.

El tema central de estas páginas es la salud y las repercusiones que sobre ella tienen las condiciones del medio ambiente, profundamente convulsionado desde la Revolución Industrial. Ésta ha elevado las esperanzas de vida de la población por encima de los 70 años debido al fuerte descenso de la mortalidad infantil. Pero en los países más desarrollados dicha media está descendiendo levemente por una serie de enfermedades como el cáncer, asma, gripe, dolencias cardiovasculares y el estrés, todas ellas fruto del progreso. Estudios recientes han demostrado que en el año 1900 tenían una incidencia sobre la mortalidad del $12 \%$, para ascender al $60 \%$ en 1980. 
Otra de las decisivas conquistas de la industrialización ha sido el descubrimiento de miles y miles de productos químicos, que si bien han conseguido el control de numerosas plagas, no es menos cierta la peligrosidad que proyectan sobre nuestro futuro. Ya hemos visto en el inicio de estas páginas cómo los laboratorios los ponen a la venta sin ningún control verdaderamente científico sobre sus repercusiones sanitarias a largo plazo. Pero aún es más desolador que se sigan vendiendo camuflados productos como el DDT, expresamente prohibido por su peligrosidad. La Real Academia de Ciencias estadounidense (1987) llegó a la conclusión de que u un $90 \%$ de los fungicidas, un $60 \%$ de los herbicidas y un $30 \%$ de los insecticidas producen cáncer» (Bermejo, 1994:29).

En los países no desarrollados también empiezan a sentirse los efectos de la industrialización porque se han visto económicamente obligados a importar las industrias más contaminantes del sistema. Pero la desnutrición y el agua contaminada siguen siendo las principales causas de las defunciones. Algo que no debe extrañarnos, pues el $80 \%$ de todas las enfermedades y el $90 \%$ de la mortalidad infantil ( 15 millones/año) tienen su origen en la contaminación de las aguas, problema que empieza a ser más que preocupante también en los paises desarrollados por la contaminación de las corrientes superficiales y de los acuíferos.

La conclusión hacia la que apuntan estas páginas es la de entender la salud como un equilibrio tan dinámico como precario, una sucesión de anticlinales flanqueados por dolencias y depresiones. $Y$ todo ello enmarcado en un entorno físico y socioeconómico, el medio ambiente del que formamos parte, pero una parte predadora y desquiciante para el resto.

\section{BIBLIOGRAFIA}

Barney, G. (1982): El mundo en el año 2000. Madrid. Tecnos.

Bermejo, R. (1994): Manual para una economía ecológica. Madrid. Libros de la Catarata.

EL PAíS (5-3-1992): "Sobre los efectos de la desaparición de la capa de ozono".

EvenARI, M. (1973): “Agricultura ecológica» en G. Durán y otros, págs. 137-150.

LOPEZ DE URALDE, J. (1992): "La marea negra de cada día". Diario 16 (24, dic.). Madrid.

PIEDROLA, G. y otros (1991): Medicina preventiva y salud pública. Barcelona. Salvat.

RuzA, F. y otros (1984): Tratado del medio ambiente. Madrid. Lafer, S.A. Vols. I y II.

Salleras, L. (1989): Educación sanitaria. Principios, métodos y aplicaciones. Madrid. Díaz Santos.

San Martín, H. (1979): Ecología humana y salud. México. Prensa médica mexicana.

Yourcenar, M. (1983: 8ª reimpr.): Memcrias de Adriano. Barcelona. Edhasa. 